\title{
On the effects of friction modelling on small punch creep test responses: a numerical investigation
}

\author{
F. Cortellino a, W. Sun ${ }^{{ }^{*}}$ and T. H. Hyde a \\ a Department of Mechanical, Materials and Manufacturing Engineering, University of \\ Nottingham, Nottingham NG72RD, UK
}

${ }^{*}$ Corresponding author: Email address: W.Sun@nottingham.ac.uk (W. Sun)

\begin{abstract}
This paper shows the results of finite element (FE) analyses of Small Punch Creep Testing (SPCT) of a P91 steel at $600^{\circ} \mathrm{C}$ using two different approaches to model the friction between the specimen and the punch. The numerical results obtained by using the "classical" Coulomb friction model (i.e. constant friction coefficient) have been compared with those obtained by a more modern formulation, which takes into account the effects of local loading conditions, i.e. the contact pressure, between the contacting bodies (the small disc specimen and the punch) on the coefficient of friction. The aim of the work is to investigate the effects of the friction formulation used for the calculations on the numerical results representing the output of the test, i.e. the variation of the punch displacement versus time and the time to rupture.
\end{abstract}

The calculations, carried out for various load levels, showed that the friction coefficient is not constant at all positions on the contacting surface between the punch and the specimen during the deformation process. The maximum value for the coefficient of friction is reached at the contact edge, which is a very important region in the specimen, because this is the position at which most of the creep deformation occurs.

As expected, the displacement versus time curve (that is usually the only output obtained from experimental SPCTs) is affected by friction formulation which is used, as this directly influences the stress and strain fields in the specimen.

Keywords: Small punch creep test; friction formulation; finite element method; P91 steel 


\section{Nomenclature}

A Plastic strain coefficient in plastic power-law constitutive model

$\mathrm{A}_{\mathrm{A}} \quad$ Apparent contact area

$a_{p} \quad$ Receiving hole radius

$A_{R} \quad$ Real contact area

B Norton's creep law stress multiplier

$C_{a} \quad$ Factor for the definition of the real contact area ratio

CDM Continuum damage mechanics

CEB Chang-Etsion-Bogy friction model

E Young's modulus

$F_{f} \quad$ Tangential contact force

$K \quad$ Shear strength of the softer material in contact

KE Kogut-Etsion friction model

$N \quad$ Normal contact force

$n \quad$ Norton's law stress exponent

$n_{P} \quad$ Plastic strain exponent in plastic power-law constitutive model

P Punch load

$p \quad$ Local contact pressure

$r \quad$ Radial position in the contact region

$\mathrm{r}_{\text {CONT }}$ Radial position of the contact edge

$\mathrm{R}_{\mathrm{s}} \quad$ Punch radius

SPCT Small Punch Creep Testing

$\mathrm{t} \quad$ Small disc specimen thickness

$t_{f} \quad$ Time to failure

$\alpha \quad$ Real contact area ratio

$\dot{\varepsilon}_{c} \quad$ Creep strain rate

$\Delta \quad$ Punch displacement

$\Delta \mathrm{u}_{\text {CLAMP }}$ Boundary conditions displacement of the upper clamp

$\varepsilon_{p} \quad$ Plastic strain

$\mu \quad$ Coefficient of friction

$\bar{\mu} \quad$ Average friction coefficient

$\mu_{L I M} \quad$ Limit value for the coefficient of friction

$v \quad$ Poisson ratio

$\sigma \quad$ Stress

$\sigma_{y} \quad$ Yield stress

$\sigma_{u} \quad$ Ultimate stress

$\tau_{f} \quad$ Contact shear stress 


\section{Introduction}

Small punch creep testing ( $\underline{\mathrm{SPCT}}$ ) is a technique which is used to obtain approximate creep properties of materials operating at high temperatures when the amount of material available for testing is very limited, such as is the case with scoop samples from in-service components, heat-affected zones (HAZ) of welds or in the development of new high temperature alloys [1-6]. Compared to other small specimen creep test methods, such as the small ring or impression creep test methods, the main advantage of the small punch creep test is that the specimen is taken to failure and therefore rupture related data is also obtained.

In view of these advantages, many researchers have investigated the methods used for the interpretation of SPCT data, in order to improve the understanding of the mechanisms governing the response of the specimen and to establish a reliable procedure to correlate the results of the small punch creep test with those of the conventional uniaxial creep test $[1,5,7-16]$.

No universally accepted data conversion method is yet available, due to the very complex mechanical response of the specimen, characterised by various interacting non-linear features, such as large deformations, large strains, non-linear material behaviour and non-linear contact (and contact friction) between the specimen and the punch.

In view of this complex behaviour, finite element ( $\underline{\mathrm{FE}}$ ) analysis is a useful tool for use in the investigation of SPCT and analytical or semi analytical solutions, developed for less complex problems, such as that of spherical contacting bodies, (see, for instance, ref. [17]) or of the indentation testing with a flat punch. In these cases, global deformations are relatively small, and are not applicable to the SPCT case.

Several finite element models of SPCT have been reported in the open literature $[1,5,7$, $12-15,18]$. In all cases, the "classical" Coulomb friction model was used with typical values assumed for the friction coefficient, $\mu$, at high temperature, being in the range 0.1 to 0.5. Dymacek et al. [7] showed that the chosen friction coefficient is a key factor in SPCT finite element modelling, and they have investigated its effects on the stress and strain distributions obtained by the FE solution [8].

The "classical" Coulomb friction theory has significant limitations, and its application is bound to induce some degree of inaccuracy in the results of SPCT finite element models.

Several researchers showed that the interaction of two contacting rough surfaces cannot be described as an intrinsic property of the interface, as assumed in the Coulomb model [19-22]. Tabor pointed out that the friction conditions between two rough contacting bodies depends on the real area of contact and the size of the asperities (related to the local stress conditions), the nature and the strength of the bond generated at the interface (related to the characteristics of the contacting surfaces) and 
the deformation and rupture modes of the material in the region in the vicinity of the contact, which is related to the local material properties [19, 22-26].

Leu modified the Tabor friction model and proposed a dry friction formulation for metal forming based on a 3D stress element under a contaminant film, taking into account the real contact area, the surface roughness, the contact conditions and the contact pressure [27]. The condition under which global sliding occurs between the contacting surfaces was described as being similar to the von-Mises failure criterion.

Chang et al. developed a multi asperity static friction model (CEB model) [28] for metallic rough surfaces. Spherical contacting asperities were assumed to have the same radii and randomly distributed heights (a Gaussian probability density function is used). The interface was assumed to be capable of transmitting tangential load until yield occurs in a single asperity (yielding inception), leading to global sliding (sliding inception). Kogut and Etsion [21, 22] pointed out that tangential load can also be transmitted after the inception of the yielding of the asperities, since a yielded asperity is surrounded by asperities which are subjected to elastic deformation and can still carry tangential load. In view of this, they introduced an improved multi asperity static friction model (KE model) [22] for elastic-plastic contacting of rough surfaces, by using finite element analysis results, and showed that the CEB model underestimates the friction coefficient. Both the CEB and KE models are multi-asperities models, and are based on different assumptions from those of Leu's formulation, i.e. the loss of tangential load carrying capability due to plastic yield of asperities.

Accurate contact modelling is of vital importance for any friction model [19]. When the "first body" approach is used, i.e. when the interacting bodies are of primary interest and are modelled without detailed description of the interacting surfaces considered as separate bodies, finite element analysis is a useful tool for improving the understanding of the contact problem between two rough surfaces [29].

In view of the limitations of the Coulomb theory and the effects of the friction coefficient on the results of SPCT finite element analyses [8], more accurate procedures for friction modelling are needed for application in SPCT numerical analyses.

In this paper, the results of SPCT finite element analyses with Leu's friction model [27] are described and they are compared with the results of analyses obtained by using the constant friction coefficient theory. Leu's friction formulation is addressed in Section 2, while the finite element model which was developed for the analyses is described in Section 3. The numerical results are described and discussed in Section 4, followed by the concluding remarks, in Section 5. 


\section{Leu's Friction model}

The classical Coulomb's friction model has been used in all of the finite element models reported in the open literature for the small punch creep test $[1,5,7,8,12-16,30,31]$. The interacting bodies are assumed to be in sticking conditions until the ratio of the transmitted shear stress to contact pressure equals the friction coefficient, $\mu$, and the inception of global sliding occurs. The friction coefficient is often assumed to be constant over the interface between the contacting bodies and it is taken to be an intrinsic characteristic of the interacting surfaces.

An explanation of the friction interaction between two contacting surfaces was proposed by Bowden and Tabor [32]. They argue that, when two surfaces are in contact under normal load, the pressure at the tips of contacting asperities is, generally, high enough for plastic flow to take place. The friction between two interacting surfaces can be related to the adhesion of strong junctions which are generated at the points of real contact and must be sheared for sliding to occur [24]. The frictional force (i.e. the force needed to produce surface sliding) can be decomposed into two contributions, i.e. the shear and the ploughing components. For metal surfaces, the ploughing component is generally smaller than that related to shear and, hereafter, it will be neglected [24, 33].

Tabor pointed out that relative sliding of two contacting surfaces is related to the combination of normal and frictional stresses and, for a 2D stress element, it takes place when equation (1) is satisfied, where $p$ represents the contact pressure, $\tau_{f}$ is the frictional stress (tangential stress at the interface due to interaction under incipient sliding conditions) and $K$ is the shear strength of the softer material [24, 27].

$p^{2}+3 \tau_{f}^{2}=3 K^{2}$

Equation (1) represents the condition of the sliding inception and does not represent the condition for an asperity to yield, as the term on the right side, $K$, is not the vonMises equivalent yield stress.

The relation between the frictional stress, $\tau_{f}$, and the shear strength, $K$, is given by equation (2), where $\alpha=A_{R} / A_{A}$, which ranges from 0 to 1 , and is the ratio between the real and the apparent contact areas, $A_{R}$ and $A_{A}$, respectively [27]. The condition $\alpha=0$ represents the "free contact state", where the real contact area is zero as well as the frictional stress, while the condition $\alpha=1$ represents the "full contact state", i.e. the real and apparent contact areas are equal, and the frictional stress needed for sliding to occur is maximum.

$$
\tau_{f}=\alpha K
$$


The real contact area between two interacting surfaces is influenced by the deformation mode of the contacting asperities (hence the loading conditions and the material properties of the interacting bodies) and the surfaces topographies (i.e. the surfaces roughnesses) [23]. However, in many practical applications for metals, plastic deformation of asperities occurs even when the contact pressure, $p$, is an order of magnitude less than the yielding pressure, $p_{0}$, of the material [23].

In ref. [27], Leu reported a hyperbolic tangent function to relate $\alpha$ to $p$, given in equation (3), where $C_{a}$ is a factor used to control the value of the hyperbolic function, assumed to be equal to 3 in ref. [27], and $\sigma_{u}$ is the ultimate stress of the softer material.

$$
\alpha=\tanh \left(C_{a} \frac{p}{\sigma_{u}}\right)
$$

The $C_{a}$ can include the effects of contaminant layers (which can change the material plasticity properties of the underlying metal [23]) and the local distribution of dislocations in the metal on the real contact area ratio, $\alpha$ [27]. It needs to be accurately evaluated.

When the contact pressure increases, more asperities come into contact, and the real contact area ratio increases. Fig. 1 shows the variation of $\alpha$ with contact pressure with material properties obtained from a P91 steel at $600^{\circ} \mathrm{C}$, for several values of $C_{a}$.

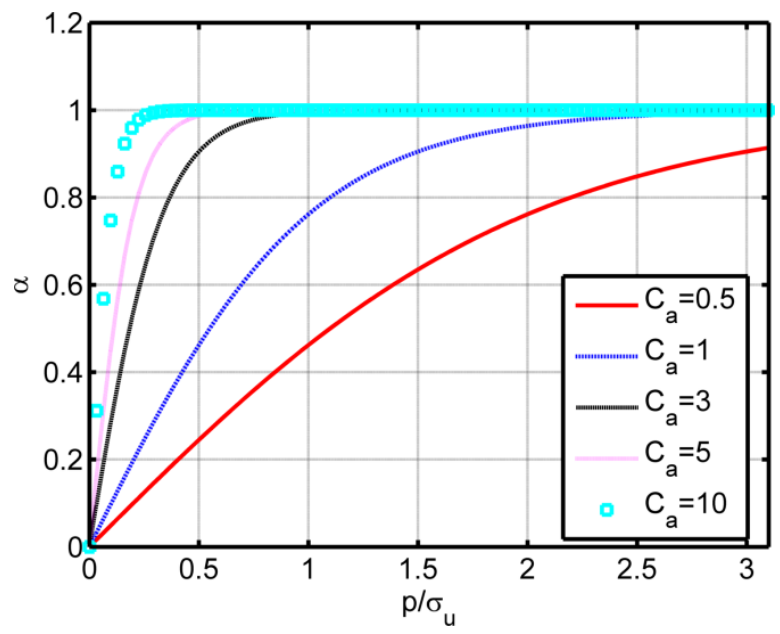

Fig. 1. Variation of $\alpha$ with contact pressure, obtained by using equation (3) for a P91 steel at $600^{\circ} \mathrm{C}\left(\sigma_{u}=\right.$ $310 \mathrm{MPa}$ ) and different values for $C_{a}$.

In ref. [27], Leu reported an expression for the friction coefficient, $\mu$, given in equation (4), obtained by using Tabor's theory. It is valid for constant friction coefficient conditions but can be localised when the contact interface is divided into several subregions each one characterised by a contact pressure value.

$$
\mu=\frac{F_{f}}{N}=\frac{\tau_{f}}{p}=\frac{\alpha}{\sqrt{3\left(1-\alpha^{2}\right)}}
$$


Equation (4) shows the dependency of $\mu$ on the real contact area, hence on local loading conditions and plastic material properties and surface topography, by the $C_{a}$ coefficient. Leu pointed out that, in "full contact" conditions $(\alpha=1)$, the friction coefficient defined by equation (4) approaches infinity. This unbounded behaviour contradicts the experimental evidence because, for $\mu=\infty$ and $\alpha=1$, at the contact surfaces, the shear stress components due to friction would be infinite even with a finite contact pressure applied [27]. However, the shear stress level in an asperity junction is finite and it is governed by the local loading conditions and by the plastic properties of the material, therefore, a limiting level to the coefficient of friction, related to the yield strength of the material, is required. For contacting ductile metals, Leu reported a limiting value of 0.577 for the friction coefficient, obtained by use of equation (1) (describing the condition of yield inception for an asperity junction) and of the von-Mises yield criterion for the material of the contacting bodies [27]. Furthermore, Tabor pointed out that the friction coefficient value is limited to values close to unity when the contacting surfaces are not placed in a vacuum atmosphere and the contacting interface a contaminant layer is found between the contacting surfaces [24].

In order to overcome this contradiction, Leu proposed a formulation based on a 3D material element, leading to the sliding condition given in equation (5), where $\sigma=\sigma_{x}=\sigma_{y}$ is the lateral pressure acting on the material element [27].

$(p-\sigma)^{2}+3 \tau_{f}^{2}=3 K^{2}$

From equation (5), a modified expression for the friction coefficient was obtained by Leu [27], given in equation (6).

$\mu=\frac{\alpha}{\sqrt{3\left(1-\alpha^{2}\right)}+\frac{\sigma}{K}}$

For a material with a power law strain hardening (given by equation (7) in uniaxial form, where $\sigma$ is the equivalent stress, $\varepsilon_{p}$ is the effective strain for plastic deformation and $A$ and $n_{p}$ are material constants), Leu obtained a relation relating $\mu$, to the real contact area ratio, $\alpha$, and the strain hardening exponent, $n_{p}$ [27], represented by equation (8) [34].

$$
\sigma=\frac{A \varepsilon_{p}^{n_{p}}}{\sqrt{3}\left[\left(1-\alpha^{2}\right)^{\frac{1}{2}}+\alpha^{\frac{n_{p}}{2}}\right]}
$$


Fig. 2 is a plot of the variation of friction coefficient with contact pressure obtained by using equations (8) and (3), for a P91 steel at $600^{\circ} \mathrm{C}$, with strain hardening exponent $n_{p}=8.693 \times 10^{-2}$ and $\sigma_{\mathrm{u}}=310 \mathrm{MPa}$ (see also Fig. 1), for different values of $C_{a}$.

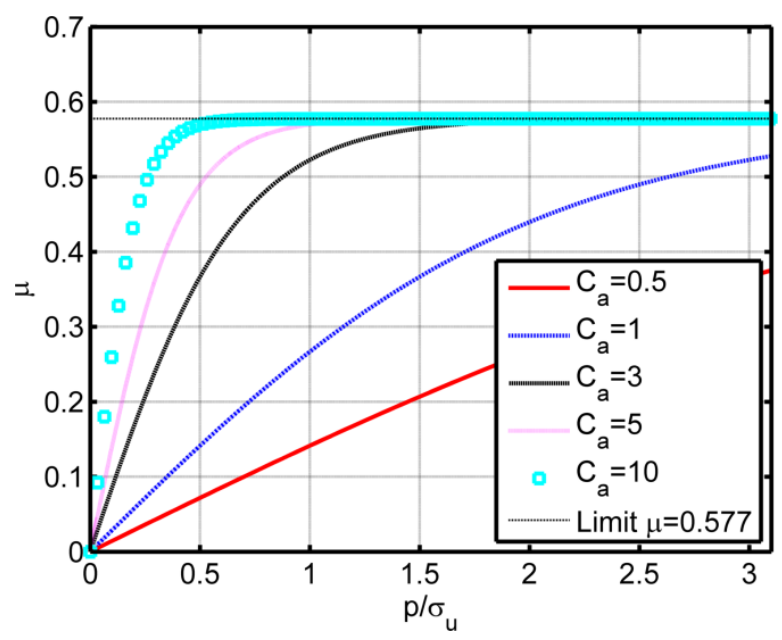

Fig. 2. Variation of the friction coefficient with the contact pressure for a P91 steel at $600^{\circ} \mathrm{C}$, with strain hardening exponent $n=0$ and $\sigma_{\mathrm{u}}=310 \mathrm{MPa}$.

When the real contact area ratio approaches unity, the friction coefficient, plotted in Fig. 2 , approaches the limiting value $\mu_{L I M}=0.577$. When the contact pressure increases, an increase of $\alpha$ (see Fig. 1), and of the number of contacting asperities, is produced, leading to an increase of friction coefficient. The limit represented by $\mu_{L I M}$ is in agreement with practical evidence [24, 27] and has been adopted in the FE analyses presented in this work. The increase of the friction coefficient with the normal load for dry contact has been related also by Hwang and Gahr to the increase of the real contact area and of the number of contacting asperities [35].

Leu's model was used in the present work because of the similarities between metal forming processes, for which the model was developed, and SPCT. During the test, large deformations and a change in shape take place in the specimen, similarly to a metal forming process and, when ductile materials are used for testing, such as P91 steel, equations (1) and (8) can be used to describe the sliding inception condition and the friction coefficient variation for the specimen.

\section{Numerical modelling of Small Punch Creep Test}

\subsection{Material constitutive model(s) for P91 steel at $600^{\circ} \mathrm{C}$}

Elastic/plastic creep analyses have been carried out for a P91 steel at $600^{\circ} \mathrm{C}$. The time independent material behaviour has been modelled as exponential elastic/plastic with isotropic hardening, based on an exponential law, equation (7) [27]. 
Creep material behaviour has been modelled by using the well-known Norton law (secondary creep approximation), represented by equation (9) in uniaxial form, where $\dot{\varepsilon}_{c}$ is the creep strain rate, $\sigma$ is the stress and $B$ and $n$ are material constants taking into account the effects of temperature [36].

$\dot{\varepsilon}_{c}=B \sigma^{n}$

Table 1 shows the chemical composition of a P91 steel [37], while Table 2 lists the corresponding elastic, plastic and creep material properties obtained at $600^{\circ} \mathrm{C}$, with the stress in $[\mathrm{MPa}]$ and time in $[\mathrm{h}]$.

\begin{tabular}{ccccccccc}
\hline $\mathbf{C}$ & $\mathbf{M n}$ & $\mathbf{S i}$ & $\mathbf{N}$ & $\mathbf{C r}$ & $\mathbf{M o}$ & $\mathbf{N b}$ & $\mathbf{C u}$ & $\mathbf{V}$ \\
\hline 0.109 & 0.443 & 0.307 & 0.042 & 8.350 & 0.948 & 0.165 & 0.152 & 0.210 \\
\hline \multicolumn{7}{c}{ Table 1 Chemical composition [\%wt] of the P91 steel used for the analyses [37]. }
\end{tabular}

\begin{tabular}{ccccccc}
\hline $\boldsymbol{E}[\mathrm{MPa}]$ & $\boldsymbol{v}$ & $\boldsymbol{\sigma}_{\boldsymbol{y}}[\mathrm{MPa}]$ & $\boldsymbol{A}$ & $\boldsymbol{n}_{\boldsymbol{p}}$ & $\boldsymbol{B}$ & $\boldsymbol{n}$ \\
\hline $1.492 \times 10^{-5}$ & 0.3 & 280 & 455.4 & $8.693 \times 10^{-2}$ & $9.795 \times 10^{-32}$ & 12.342 \\
\hline Table 2 & Material properties (with the stresses in [MPa] and time [h]) obtained for a P91 steel at $600^{\circ} \mathrm{C}$.
\end{tabular}

\subsection{FE model of SPCT}

In view of the symmetry of the problem, a $2 \mathrm{D}$ axis symmetric $\mathrm{FE}$ model has been developed for the numerical analyses using the nonlinear commercial software ABAQUS Standard. For the solution of the creep step, an implicit integration scheme was chosen because the time span covered in the analyses is relatively large and no impulsive phenomena are modelled. The creep time increment was controlled by the solver andan initial value of $1 \times 10^{-30} \mathrm{~h}$ was used in order to achieve convergence in the early steps of the analyses. Furthermore, the maximum time increment was limited to $10 \mathrm{~h}$, in order to have an accurate solution throughout the creep step and an accurate sampling of the output. It should be noted that, for the present work, static analyses were performed, and no inertia effects of any sort are taken into account.

The specimen was modelled as a deformable part, while the punch, the support and the upper clamp have been modelled as rigid bodies.

The geometry of the model conforms with the range recommended by the CWA 15627 draft code of practice by CEN [11] on small punch testing of metallic materials, with specimen's thickness, $t$, and diameter of 0.5 and $8 \mathrm{~mm}$, respectively, punch radius, $R_{s}$, of $1.25 \mathrm{~mm}$, receiving hole radius, $a_{p}$, of $2 \mathrm{~mm}$ and lower clamp radius of $0.25 \mathrm{~mm}$.

Fig. 3 (a) shows the solid model rendering of a quarter section of the test rig, while Fig. 3 (b) is the corresponding section with dimensions. 


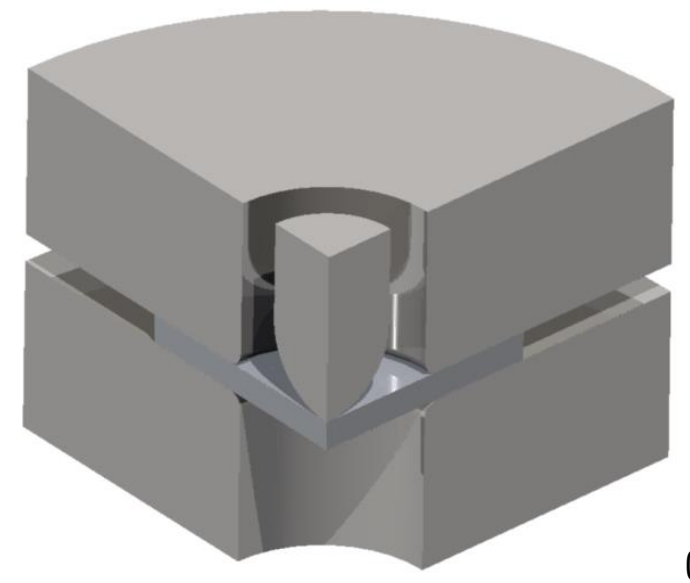

(a)

(b)

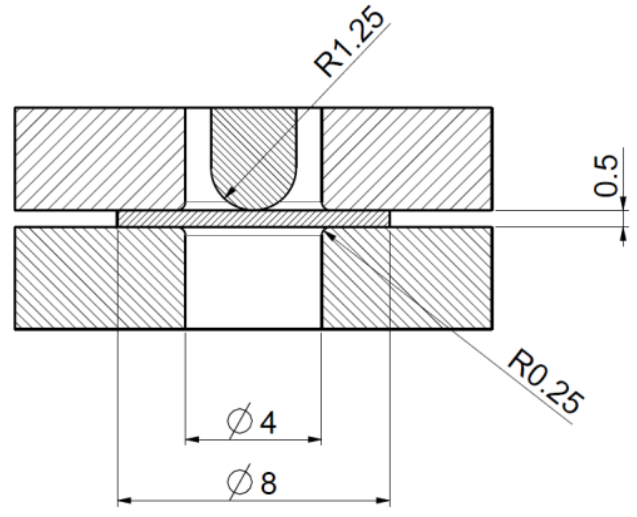

Fig. 3. SPCT configuration: (a) rendering of the section of the solid model; (b) dimensions of the test rig $[\mathrm{mm}]$.

Different load levels, ranging between 34 and $42 \mathrm{~kg}$, have been applied to the punch in the analyses and suitable boundary conditions have been applied to the rigid bodies modelling the test rig. The radial and axial translations and the rotation around the axis of symmetry of the support have been constrained. The horizontal translation and the rotation of the punch and of the upper clamp have also been constrained. The clamping load has been applied by imposing a vertical displacement to the upper clamp. Fig. 4 schematically shows the loads and the boundary conditions applied to the FE model.

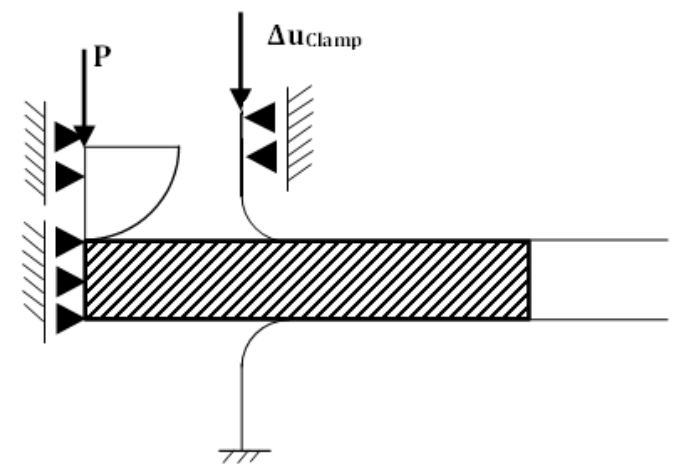

Fig. 4. Loads and boundary conditions applied to the FE model of SPCT.

The FE mesh adopted in the analyses has been developed taking into account the different stress and strain fields in various regions of the specimen and at various stages of the specimen deformation. A mesh sensitivity analysis was conducted in order to minimise numerically induced fluctuations of the contact pressure during the creep solution and, in the expected contact area between the punch and the specimen; this has led to an "optimised" element size equal to 0.0024 times the punch radius. Accurate modelling of the region close to the edge of contact between the specimen and the punch is of critical importance in predicting SPCT behaviour [14], as well as that close to the clamps, where a severe bending deformation stress concentration occurs. These two regions in the specimen have relatively small element sizes. A coarser mesh has been adopted for the other regions. In Fig. 5, the variation of the contact pressure versus the 


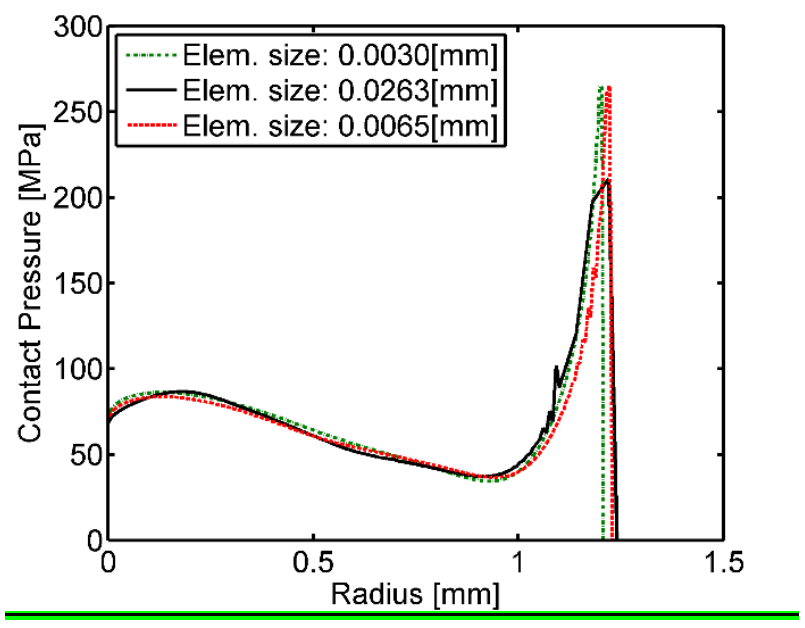

Fig. 5. Mesh sensitivity of the variation of contact pressure versus radial coordinate at

$25 \%$ of the time to rupture, with a load of $34 \mathrm{~kg}$.

Fig. 6 is a swept representation of the mesh used for the FE analyses. It consists of 15253 nodes and 14892 quadrilateral, 2D axis-symmetric, linear elements. The hybrid elements formulation (based on the independent interpolation of the pressure stress, coupled with the displacement solution) has been adopted, in order to avoid numerical difficulties generated when incompressible deformations occur. A reduced integration scheme was used in order to overcome problems related to the locking of elements. This can be caused by "parasite" stiffness components arising when bending deformation is significant, as at the early stages of the creep step in the present analyses. The CAX4HR element type, available in ABAQUS, was used.

Surface to surface contact interactions have been used for all of the contacting pairs. The contact elements were automatically generated by the solver 11144 elements added to those defined by the user) and consist of stiff springs which, once activated, apply the contact forces to the contact nodes on master and slave surfaces (see also ref. [38]). The activation of contact elements occurs when the interference between the contact nodes is less than the specified tolerance ( 0 in the present analyses, therefore no soft-contact option was chosen). The stiffness of the contact elements varies non-linearly with the contact penetration (i.e. non-linear penalty formulation) and was found to be a critical feature of FE analyses when material flow, due to plasticity and creep, is included, as it directly influences the convergence and the accuracy of the solution. Also the slip tolerance under stick conditions (identifying the tangential stiffness of contact 
elements) significantly affects the convergence of both the elastic/plastic and creep steps of the FE analysis.

During the test, the small disc specimen undergoes severe changes in its shape, since it gradually turns into a conical shape. In order to account for large deformation, the geometrical non-linearity formulation (GNL in ABAQUS) has been used in all of the analyses.

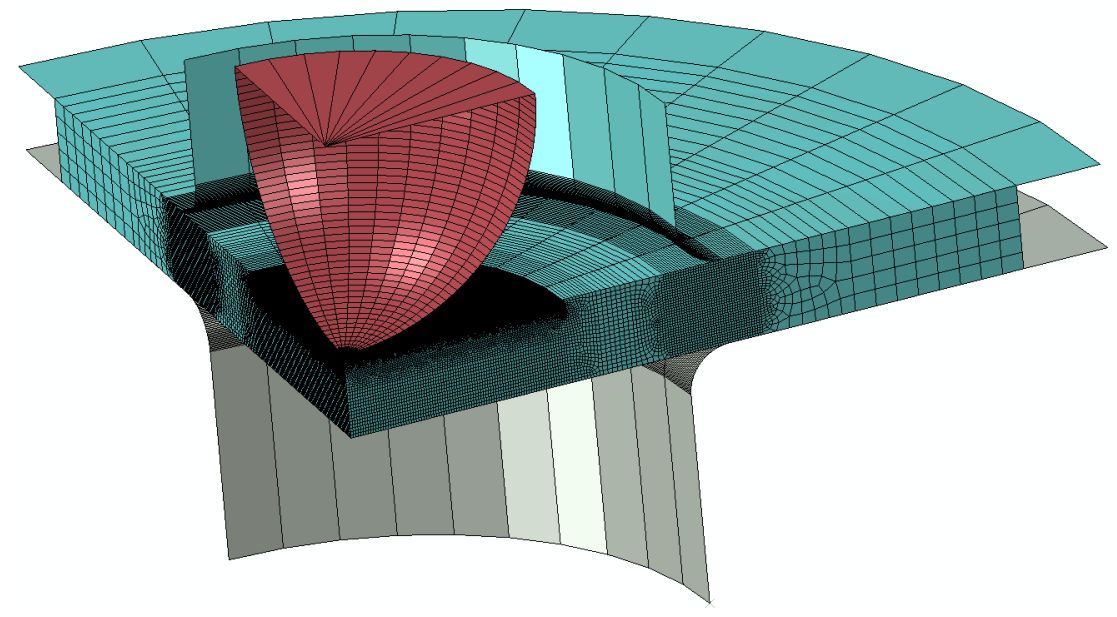

(a)

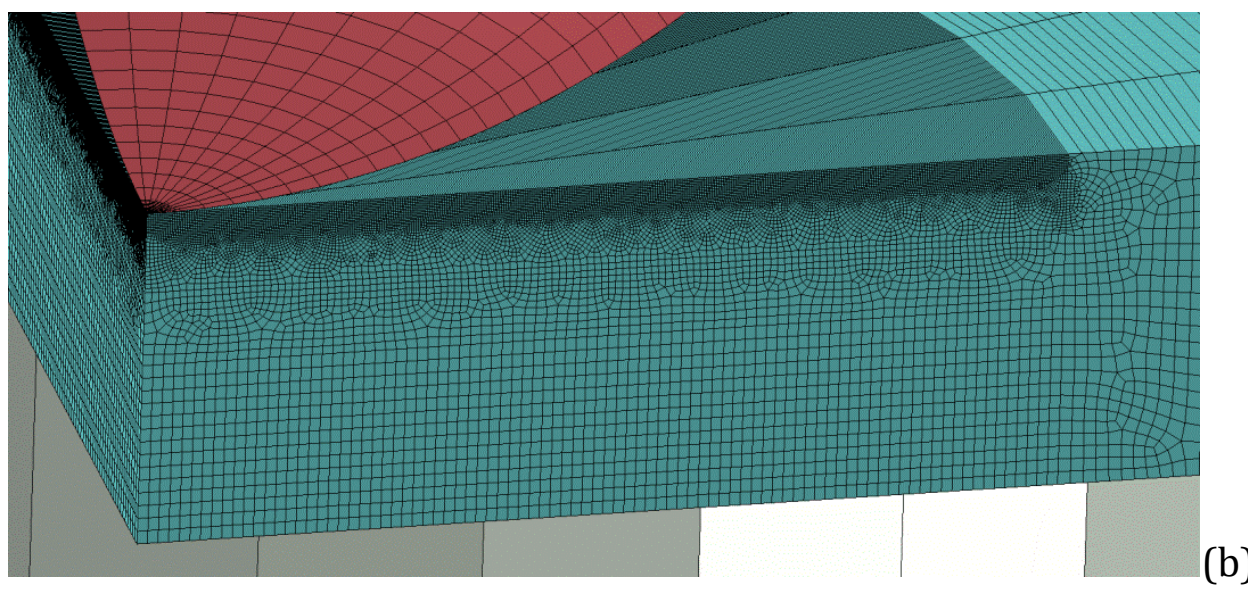

Fig. 6. (a) Swept representation of the 2D axis-symmetric mesh adopted in the FE analyses and (b) detailed view of the mesh in the unsupported region of the specimen.

\subsection{Modelling of the variable coefficient of friction}

The friction interaction for the contact between the punch and the specimen has been assumed to vary with local loading conditions, according to Leu's model, equation (8). A FRIC_COEF user subroutine has been implemented in order to include this friction formulation into the numerical solver. 
The subroutine is called at each contact point and can calculate the value of $\mu$ as a continuous function of contact pressure. The FRIC_COEF subroutine has also the capability to describe the variation of the friction coefficient with the temperature and the sliding rate. In the present work, the temperature is assumed to be constant and the sliding rate is low, thus only the dependency of $\mu$ on the contact pressure (see equation (8)) has been modelled, i.e. it neglects the dependency on temperature and sliding rate.

In order for the calculation to be performed, also the derivatives of $\mu$ with respect to these three quantities (i.e. contact pressure, sliding rate and temperature) need to be fed into the subroutine. The effects of field variables defined by the user can also be taken into account.

The round radius of the lower die has a remarkable effect on the failure time of the specimen as it governs the bending deformation, taking place near the supported region of the specimen, and the stress intensification near the contact boundary, as also reported in ref. [39]. Therefore, the interaction between the specimen and the clamps significantly affect the results of FE calculations of SPCT and, in the present work, it was modelled as a frictional contact [7]. The friction coefficient between the clamps and the specimen has been assumed to be constant, because only the effects of the friction formulation between the punch and the specimen have been investigated. The upper bound of equation (8), i.e. a constant coefficient of friction of $\mu_{\mathrm{LIM}}=0.577$, is used for the coefficient of friction between the specimen and the upper and lower dies.

\section{Numerical results and discussion}

Several elastic/plastic/creep analyses have been carried out using the FE model described in Section 3, using both variable friction formulation (equation (8)) and classical Coulomb's theory, with $\mu$ ranging between 0.1 and 0.5 , for the punch/specimen interaction. The contact between the specimen and the clamps is assumed to exhibit a constant coefficient of friction, equal to $\mu_{\mathrm{LIM}}$, in all of the FE analyses.

At the beginning of the creep step (elastic/plastic FE analysis), the elastic and plastic deformations, occurring under the contact surface, affect the local loading conditions (i.e. the variation of contact pressure with radial position) in the contact area. These local conditions govern the value of the coefficient of friction (see equations (3) and (8)) and, in turn, the stress and strain fields resulting in the specimen.

Fig. 7 shows contour plots of the von-Mises equivalent plastic strains at the beginning of the creep step for three different load cases, with punch loads ranging from 34 to $42 \mathrm{~kg}$. In the region close to the interface between the punch and the specimen, the plastic strains are predicted to be larger than $10 \%$ for all of the load levels, hence the effect of plasticity on the variation of the contact pressure is significant. 
The maximum von-Mises equivalent plastic strain is located at the bottom surface of the specimen in an annular region approximately $0.5 \mathrm{~mm}$ away from the symmetry axis, similar to the critical region identified by Dymacek et al. for small punch creep test specimen [7]. In view of its magnitude, the plastic flow in the critical region of the specimen is not negligible for all of loads used in the analyses.

From Fig. 7 it can be observed that plastic deformation influences the response of the specimen for all of the load levels, hence it important to take it into account.
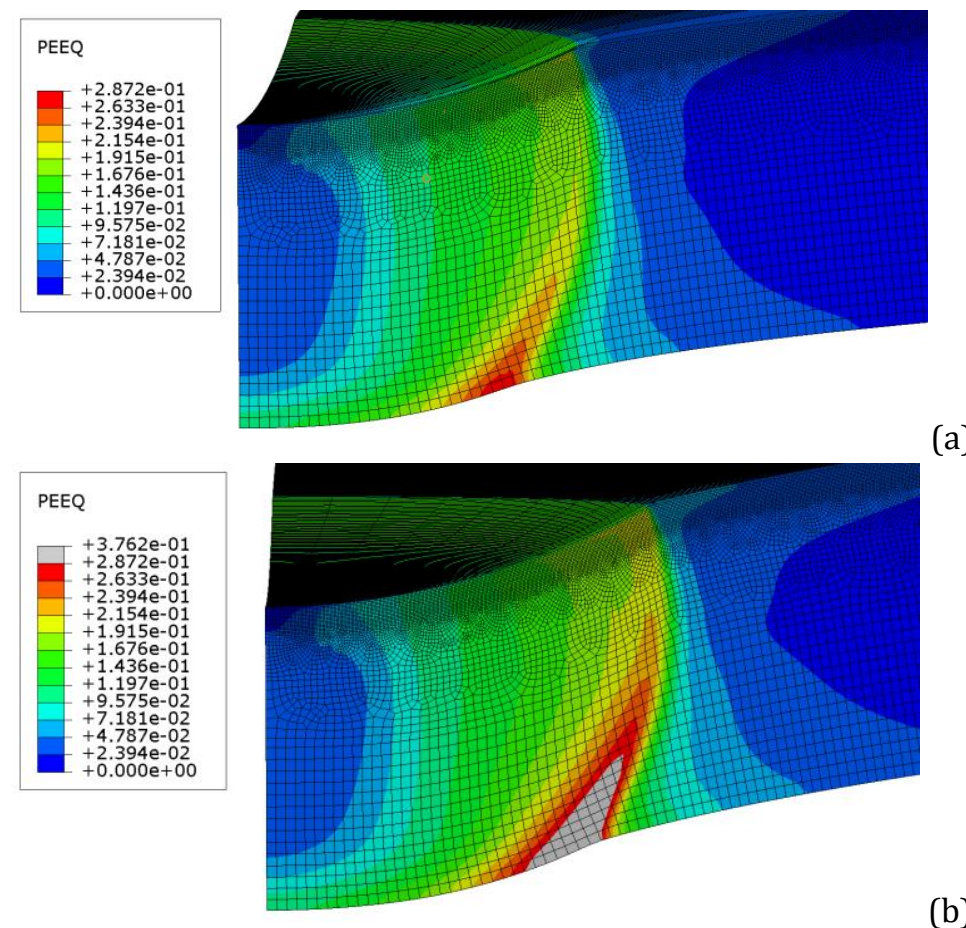

(a)

(b)

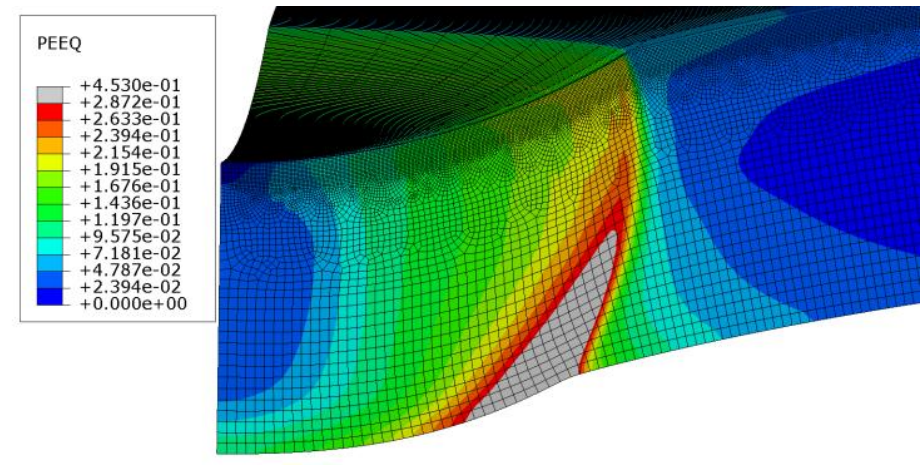

(c)

Fig. 7. Contour plot of the von-Mises equivalent plastic strain, in absolute value, at the beginning of the creep step with load levels of 34 (a), 38 (b) and $42 \mathrm{~kg}$ (c).

Fig. 8 shows the contour plots of the von-Mises equivalent stress at the beginning of the creep step with the load ranging between 34 and $42 \mathrm{~kg}$. 


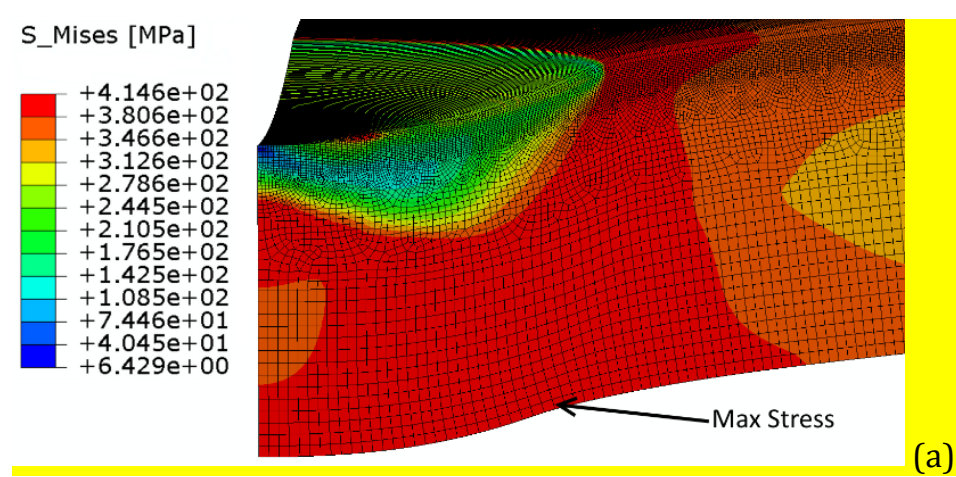

(a)

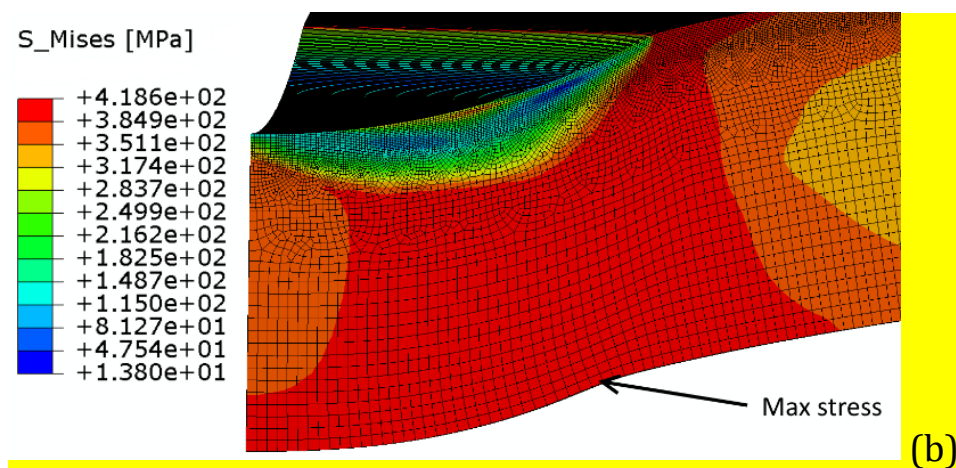

(b)

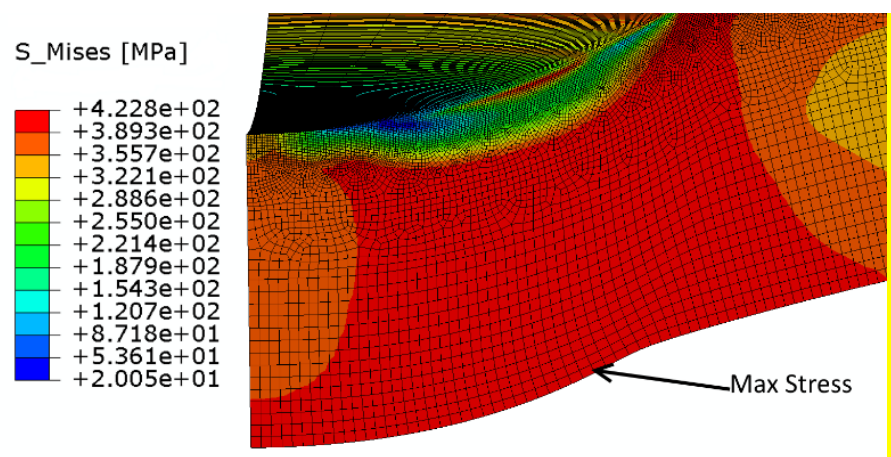

(c)

Fig. 8. Contour plot of the von-Mises equivalent stress [MPa] at the beginning of the creep step with load levels of $34(\mathrm{a}), 38$ (b) and $42 \mathrm{~kg}$ (c).

During the small punch creep test, the specimen undergoes large global deformation which, indirectly, affects the local contact loading conditions, i.e. the variation of the local contact pressure, $p$, with radial position and time. An increase of $p$ on an element of the contact surface brings more asperities into dry contact, thus the friction coefficient, $\mu$, increases on that element and, hence, more tangential load can be carried before global sliding occurs [35].

Fig. 9 shows the plots of the punch displacement versus creep time for the three load levels $(34,38$ and $42 \mathrm{~kg})$ used in the numerical analyses. The cases include both variable and constant friction coefficient conditions. $C_{a}=3$ has been used in the cases with variable friction coefficient (see equation (3)) for consistency with ref. [27]. 
From Fig. 9, the effect of the coefficient of friction formulation on the results of FE analyses can be observed and, for the test cases with constant $\mu$, consistency with the results reported in ref. [8] is found. For a given load level, when the coefficient of friction increases, the minimum displacement rate decreases and the failure time increases. In this work, as Norton's law was used, the failure time has been defined as the creep step time when the solution does not converge.
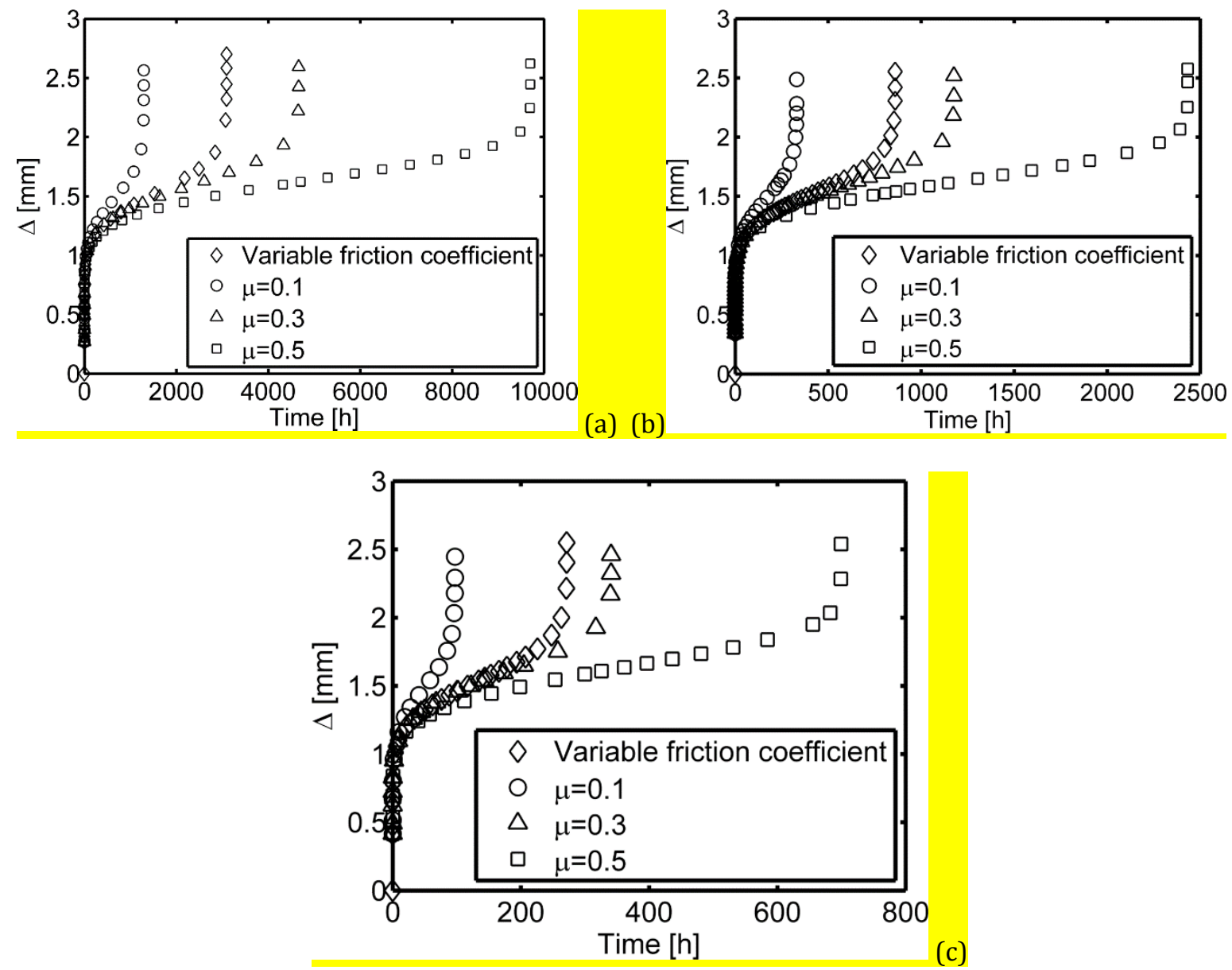

Fig. 9. Plot of the punch displacement versus time for a load of 34 (a), 38 (b) and $42 \mathrm{~kg}$ (c). $C_{a}=3$ for the variable friction coefficient test cases.

The influence of $\mu$ on SPCT output can be explained by considering the effect of the distributed forces, generated by friction, on the stress field of the specimen. Friction forces induce a local stress field that opposes the relative global motion (sliding) of the interacting bodies. Consequently, a bending moment, which contrasts the global deformation of the specimen, is generated because of the equilibrium.

For a given punch load level, when the friction coefficient increases, the magnitude of the friction forces increases as well. In turn, the magnitude of the bending moment contrasting the global deformation of the specimen increases. This causes a decrease in the minimum displacement rate and an increase in the failure time. 
In order to evaluate the effects of the $C_{a}$ parameter (see equation (3)) on the numerical results, FE analyses have been performed using the variable friction formulation, equation (8), with $C_{a}$ ranging from 1 to 20. The results of the analyses (i.e. the variation of the punch displacement with time) are shown in Fig. 10 for a load of $38 \mathrm{~kg}$.

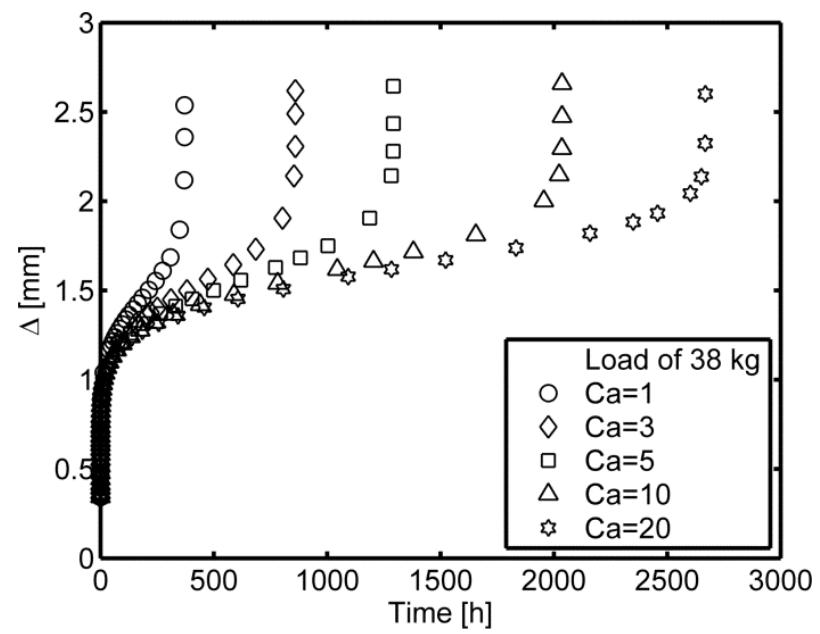

Fig. 10. Plot of the punch displacement versus time for a load of $38 \mathrm{~kg}$ and different values of $C_{a}$.

The minimum displacement rate and the failure time are highly sensitive to the $C_{a}$ parameter, especially in the range between $C_{a}=1$ and $C_{a}=10$. When $C_{a}$ increases, the failure time increases and the minimum displacement rate decreases. This behaviour is due to the effect of $C_{a}$ on the real contact area ratio, $\alpha$ (equation (3)), and, in turn, on the coefficient of friction (equation (8)). In view of the results shown in Fig. 10, an accurate estimation of $C_{a}$, from surface roughness and material properties of the specimen, is needed in order to obtain accurate estimations of $\mu$ [27].

Fig. 11 reports the variation of the contact pressure versus time and radial coordinate normalised with respect to the radial position of the contact edge, $\mathrm{r}_{\text {cont }}$, obtained from the results of the FE analyses carried out by using Leu's friction formulation with a punch load of 34,38 and $42 \mathrm{~kg}$.

For all of the load levels, the contact pressure exhibits a peak value at the contact edge during the whole time span covered by the analyses except from the time to rupture, when the peak pressure value is at some distance from the contact edge. The variation of the contact pressure is governed by the reaction of the specimen to the punch load and by the hemispherical shape of the punch head. When creep proceeds in the specimen, the reaction of the structure to the load generates a bending moment which tends to rotate an annular section of the material in the contact edge region. This rotation causes a decrease in the contact pressure near the axis of symmetry and an increase of pressure near the 'hinge' of rotation, i.e. the contact edge. 

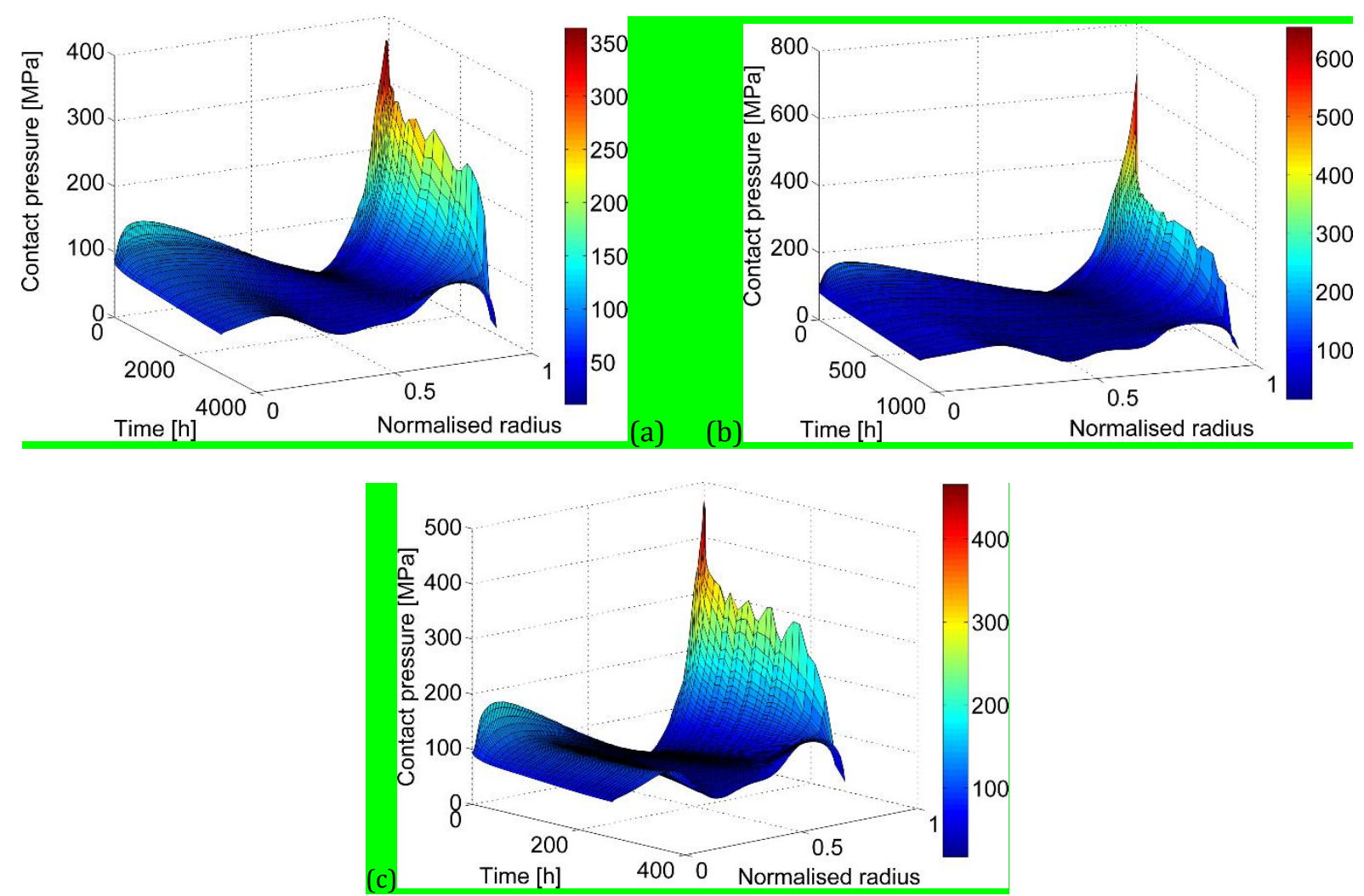

Fig. 11. Variation of the contact pressure with normalised radius, $\frac{\mathrm{r}}{\mathrm{r}_{\text {cont }}}$ and creep step time for load levels of $34 \mathrm{~kg}(\mathrm{a}), 38 \mathrm{~kg}(\mathrm{~b})$ and $42 \overline{\mathrm{kg}(\mathrm{c})}$.

The variation of the coefficient of friction on the contact surface, over the creep step, has been evaluated from the FE results performed by using Leu's friction formulation (equation (8)). Fig. 12 is a plot of the coefficient of friction over the contact region for a punch load of $34 \mathrm{~kg}$ at different creep times, while Fig. 13 shows the variation of the friction coefficient with creep step time and the radial coordinate normalised with respect to the contact radius, for $C_{a}=3$.

The coefficient of friction has been found to vary significantly over the area of contact and. During most of the creep step, its maximum value has been found to occur at the contact edge (see Fig. 12 and Fig. 13). This variation is related to the mode of deformation of the specimen, which is characterised by the effects of material nonlinearities (such as plasticity and creep), varying geometrical stiffness of the specimen (effects of large deformations and necking), and the severe loading conditions which occur at the contact edge.

During creep deformation, at the centre of the specimen, a minimum cusp point can be observed in the distribution of $\mu$ (see Fig. 12 and Fig. 13). This can be related to the global response of the small disc specimen, related to the axis-symmetric geometry and the material constitutive model. 


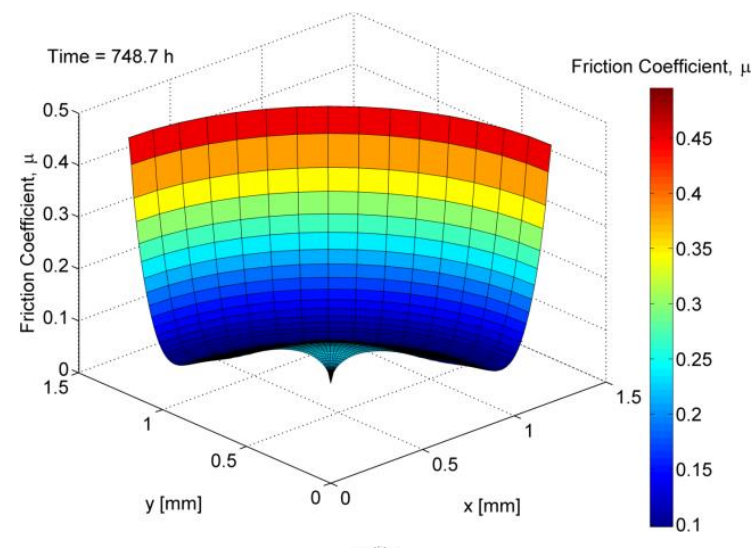

(a)(b)
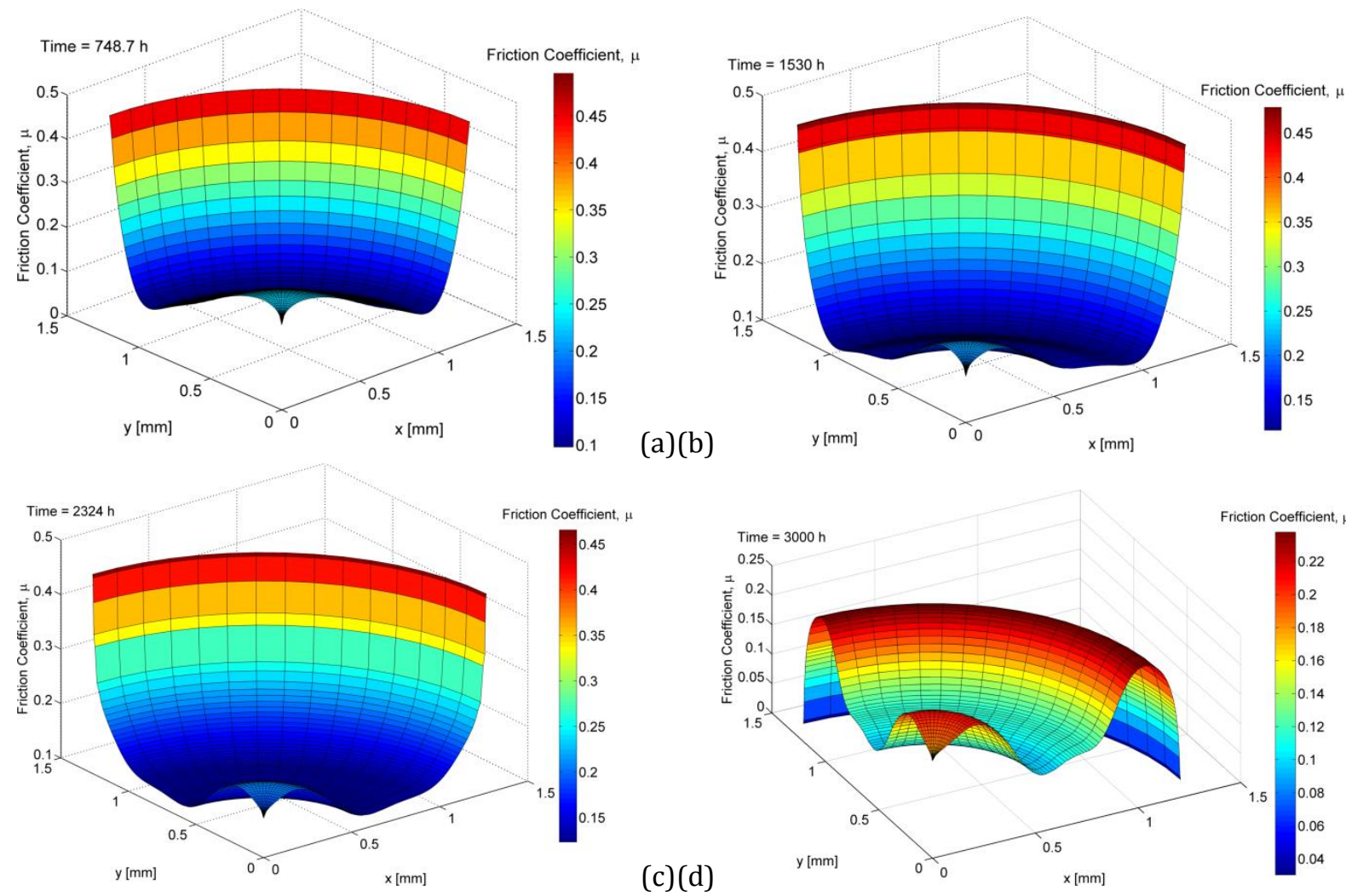

(c) (d)

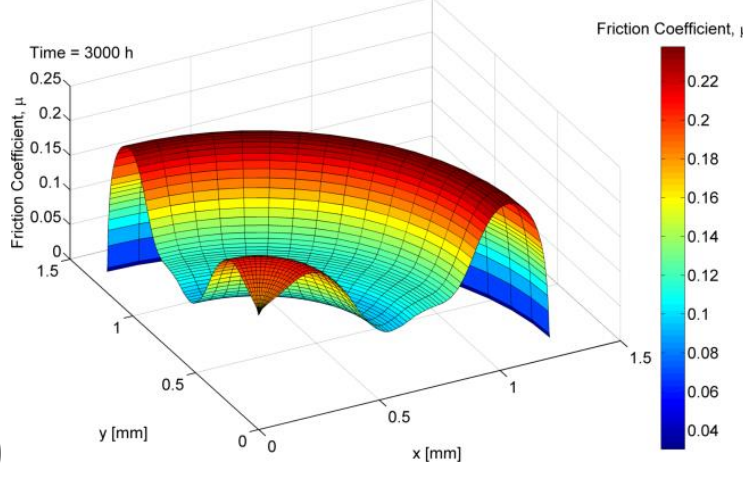

Fig. 12. Distribution of the coefficient of friction, $\mu$, at creep step time $t=0.25 t_{f}(a), t=0.5 t_{f}(b), t=0.75 t_{f}(c)$, $t=0.99 \mathrm{t}_{\mathrm{f}}(\mathrm{d})$, for a load level of $34 \mathrm{~kg}$, over a quarter section of the contact surface.

As creep proceeds in the specimen, the loading mode progressively changes from bending dominant to "membrane stretching" dominant and the stress field redistributes within the specimen. The effects of the transition are visible also in Fig. 12 and Fig. 13. Furthermore, the average magnitude of $\mu$ decreases with time, since the apparent contact area progressively increases under a constant punch load.

The stress redistribution, related to creep deformation, modifies the shape of $\mu=\mu(r)$ (see Fig. 12). After a creep step time of approximately $0.5 t_{f}$, the friction coefficient remains almost constant at its minimum value in the annular region between $0.4 r_{\text {cont }}$ and $0.7 r_{\text {cont }}$, where $r_{\text {cont }}$ is the radial position of the contact edge. This region expands when the creep step proceeds. The distribution of the coefficient of friction is then drastically modified when the failure time is approached and the maximum value of $\mu$ is at the radial position $r / r_{\text {cont }} \cong 0.9$ (see Fig. 12 and Fig. 13).

The peak level of the friction coefficient is located at the contact edge during the majority of the creep step of the analyses because, in view of equations (3) and (8), the friction coefficient increases with and increase in the contact pressure and, from Fig. 11, the peak level for the contact pressure is also located at the edge of contact for most of the duration of the analyses. Therefore, the variation of the friction coefficient reported in Fig. 13 is consistent with that of the contact pressure shown in Fig. 11. 
The punch load does not affect the variation of $\mu=\mu(\mathrm{r})$ to a large extent during creep analyses, as the governing deformation modes are the same for the three of the load levels adopted.

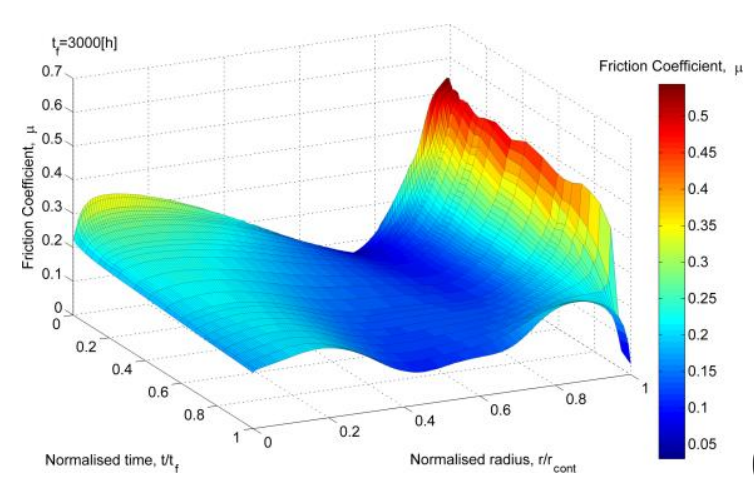

(a) (b)
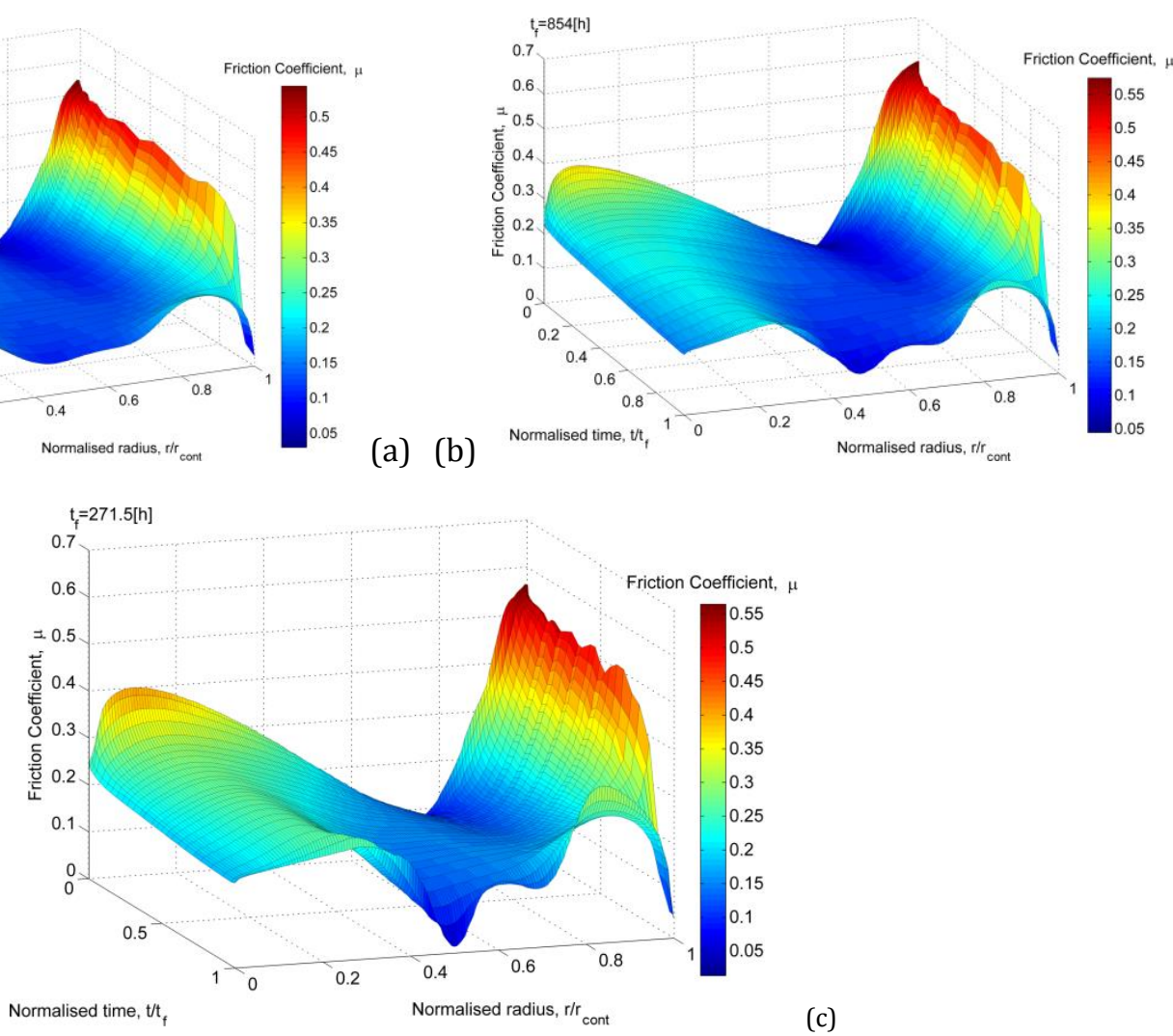

(c)

Fig. 13. Variation of the coefficient of friction with normalised radius, $\frac{\mathrm{r}}{\mathrm{r}_{\text {cont }}}$, and creep step time for load levels of $34 \mathrm{~kg}(\mathrm{a}), 38 \mathrm{~kg}(\mathrm{~b})$ and $42 \mathrm{~kg}(\mathrm{c})$.

From Fig. 9, the displacement curves obtained from the cases with variable friction formulation were found to be similar to those calculated by using a constant "equivalent" coefficient of friction.

In order to investigate the possibility to identify an "equivalent friction coefficient", some additional FE analyses were performed using Coulomb's theory, with $\mu$ of 0.22 (for a load of $34 \mathrm{~kg}$ ), 0.24 (for a load of $38 \mathrm{~kg}$ ) and 0.26 (for a load of $42 \mathrm{~kg}$ ). The values of minimum displacement rate and failure time obtained by these three analyses were similar to those obtained by using the variable friction formulation of equation (8) with the respective loads. This shows that a value of the coefficient of friction, capable of including the effects of the contact pressure on FE results, cannot be identified, as different load levels lead to different values of the "equivalent friction coefficient", which increase with the load. 
In the regions of the specimen far from the interface with the punch, use of constant "equivalent" values of the coefficient of friction lead to stress and strain distributions similar to those obtained from the variable friction cases. However, in the vicinity of the punch/specimen interface, the stress and strain fields differ significantly.

Furthermore, the "equivalent" friction coefficient is not equal to the average value of the coefficient of friction, $\bar{\mu}$, obtained from Leu's formulation. The average value $\bar{\mu}$ ranges from 0.19 to 0.21 for the three load levels used (see Fig. 12). This discrepancy between $\bar{\mu}$ and the "equivalent" value is related to the highly non-linear response of the specimen. It suggests that different regions of the punch/specimen contact surface have different effects on the stress and strain fields, affecting the bending and membrane stretching response. For example, the peak of the friction coefficient occurs at the contact edge and shows there to be a higher influence on the test output than other regions of the contact area, as the "equivalent" value of $\mu$ is always higher than $\bar{\mu}$.

Fig. 14 is a Scanning Electron Microscope (SEM) image of a P91 steel SPCT specimen tested at $600^{\circ} \mathrm{C}$. The image shows the top surface of the specimen with the test interrupted at approximately $90 \%$ of the time to rupture. A remarkable wear can be noticed in Fig. 12 at the edge of the contact region between the punch and the specimen. The high degree of wear indicates that high localised shear stresses characterise the interaction between the punch and the specimen. This observation is consistent with the variation of the coefficient of friction over the contact region reported in Fig. 11, where the peak value for $\mu$ is at the contact edge.

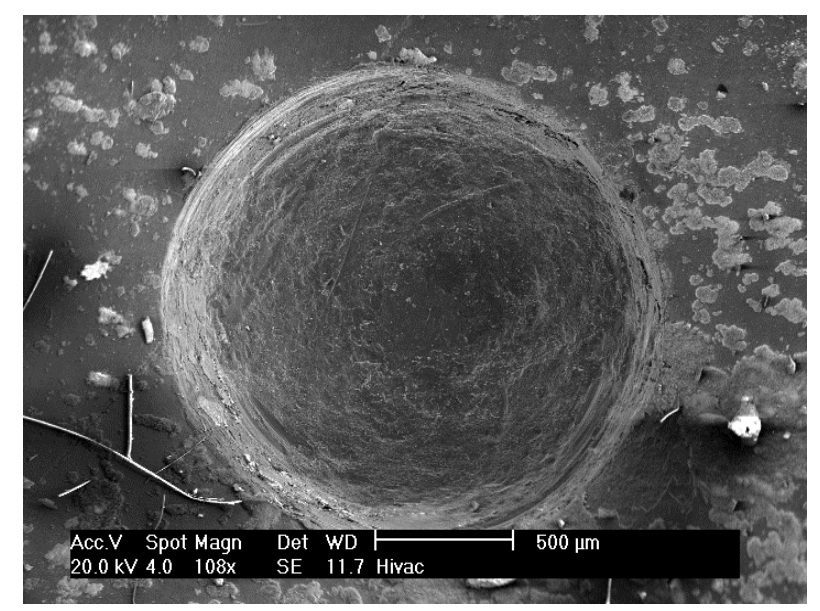

Fig. 14. Top surface of an SPCT specimen of a P91 steel at $600^{\circ} \mathrm{C}$.

When a constant friction formulation, i.e. 'classical' Coulomb's theory, is used, the local friction force is linearly proportional to the contact pressure, therefore, in view of Fig. 11 , the local friction forces applied by the punch to the specimen would also have a peak at the contact edge. However, by using Leu's formulation, the increase in the local friction forces with the contact pressure is more than linear because also the coefficient 
of friction increases with an increase in contact pressure (modelling the increase in the tangential load carrying capability of the junction asperities due to the increase in the local closing contact force).

In the present work, since Norton's creep law (steady-state creep approximation) has been used, material creep damage and deterioration are not taken into account. Therefore, the "tertiary SPCT region", i.e. the region where the punch displacement rate drastically increases (see Fig. 9 and Fig. 10), is caused by progressive necking of the critical annular region of the specimen (i.e. geometrical softening, see also refs. [7, 14]), accounted for by the GNL formulation. This assumption affects the accuracy of the FE analyses, as the material in the specimen undergoes strain levels which are compatible with the tertiary creep regime even at the beginning of the test [1]. An improvement in the accuracy of numerical results could be obtained by using continuum damage mechanics (CDM) creep constitutive models (such as the Kachanov-Rabotnov or the Liu \& Murakami CDM constitutive models), which are capable of describing the whole creep curve, including the tertiary creep regime and the effects of creep damage [40].

\section{Concluding remarks}

Elastic/plastic/creep FE analyses of a small punch creep test specimen were carried out with the aim of investigating the effects of local loading conditions, i.e. contact pressure, on the distribution of the coefficient of friction. A variable friction coefficient formulation, developed for metal forming by Leu [27], linking the real contact area, thus contact pressure, material properties and contact surfaces roughness to the coefficient of friction, was adopted in the current work to model the tangential behaviour of the specimen/punch interaction.

The results of the analyses showed that the friction coefficient varies over the contact surface during creep step. The large deformation of the specimen and the plastic and creep material flows govern the local contact loading conditions and, in turn, the variation of the coefficient of friction, which was found to significantly influence the variation of the punch displacement versus time. However, in the open literature, there is currently no experimental evaluation of the coefficient of friction between the punch and the specimen during SPCT, therefore the validation of the results reported in this paper is not straightforward to achieve. Although the variation of $\mu$ has been identified, an accurate estimation of its value is still not possible because the numerical results are affected by the $C_{a}$ parameter, which is used to identify the real contact area and is related to material properties and surface roughness of the specimen. Further investigation might include the calibration of Leu's friction formulation by experimental tests, such as a ball on disc experiment, in order to identify a realistic value of the $\mathrm{C}_{\mathrm{a}}$ parameter for the materials used in this study. The calibration will also allow to identify the values of the coefficient of friction for SPCT, while only its variation over the contact area could be evaluated by a purely numerical approach. 
A procedure to accurately identify this parameter is still not available; this would enable an important improvement over present FE models.

The friction formulation could be improved by taking into account also the "thermally activated adhesion" and investigating its effects on FE results [41] and, at the moment, validation of numerical results is not possible because corresponding experimental results are not available.

In the analyses reported in this work, the failure of the specimen is related just to geometrical softening (necking) of the specimen, as the material deterioration, characteristic of tertiary creep, is neglected (Norton's creep law has been used) and, furthermore, the effects of plastic strains on creep material response are not modelled. In view of these factors, it is concluded that the accuracy of the numerical solution can be greatly improved by using a more sophisticated constitutive model which is capable to take into account creep damage and plasticity/creep interaction.

Furthermore, the present work was carried out by analysing a force-controlled test and significant effects of the friction formulation on minimum punch displacement rate and time to rupture of the specimen were observed. A further investigation would concern the behaviour of the specimen in the displacement-controlled variation of the SPCT, as described in ref. [29], when different friction formulations are adopted. The friction formulation would influence the stress distribution in the specimen and, as a consequence, the balance between the force applied by the punch and the bending and stretching reactions of the specimen to that load. In turn, the variation of the punch load versus the punch displacement (i.e. the output of this typology of SPCT) is expected to be affected by friction formulation.

\section{Acknowledgments}

The authors would like to acknowledge EPRI for their financial support to this research.

\section{References}

1. Hyde, T.H., M. Stoyanov, W. Sun, and C.J. Hyde, On the interpretation of results from small punch creep tests. The Journal of Strain Analysis for Engineering Design, 2010. 45(3): p. 141-164.

2. Evans, M. and D. Wang, Stochastic modelling of the small disc creep test. Materials Science and Technology, 2007. 23(8): p. 883-892.

3. Evans, M. and D. Wang, Optimizing the sensitivity of the small-disc creep test to damage and test conditions. The Journal of Strain Analysis for Engineering Design, 2007. 42(5): p. 389-409.

4. Evans, M. and D. Wang, The small punch creep test: some results from a numerical model. Journal of Materials Science, 2008. 43(6): p. 1825-1835.

5. Evans, R.W. and M. Evans, Numerical modelling of small disc creep test. Materials Science and Technology, 2006. 22(10): p. 1155-1162.

6. Parker, J.D. and B. Wilshire, Non-destructive life assessment of high temperature components and weldments. International Journal of Pressure Vessels and Piping, 1992. 50(1-3): p. 337-347. 
7. Dymáček, P. and K. Milička, Creep small-punch testing and its numerical simulations. Materials Science and Engineering: A, 2009. 510-511(0): p. 444-449.

8. Dymacek, P., S. Stanislav, K. Milicka, and F. Dobes, Influence of friction on stress and strain distributions in small punch creep test models. Key Engineering Materials, 2010. 417-418: p. 561564.

9. Hurst, R.C. Standardisation-A Route to Enhancing the Acceptability of the Small Punch Creep Test. in ECCC Creep Conf., 2005. 2005. London (UK): DEStech Publications, Inc.

10. Milička, K. and F. Dobeš, Small punch testing of P91 steel. International Journal of Pressure Vessels and Piping, 2006. 83(9): p. 625-634.

11. CEN, CWA 15627 Workshop agreement: Small Punch Test Method for Metallic Materials. 2006, European Commitee for Standardisation: Brussels.

12. Chen, J., Y. Ma, and K. Yoon, Finite element study for determination of material's creep parameters from small punch test. Journal of Mechanical Science and Technology, 2010. 24(6): p. 1195-1201.

13. Ling, X., Y. Zheng, Y. You, and Y. Chen, Creep damage in small punch creep specimens of Type 304 stainless steel. International Journal of Pressure Vessels and Piping, 2007. 84(5): p. 304-309.

14. Ma, Y.W., S. Shim, and K.B. Yoon, Assessment of power law creep constants of Gr91 steel using small punch creep tests. Fatigue \& Fracture of Engineering Materials \& Structures, 2009. 32(12): p. 951960.

15. Yang, Z. and Z. Wang, Relationship between strain and central deflection in small punch specimens. International Journal of Pressure Vessels and Piping, 2003. 80: p. 397-404.

16. Zhou, Z., Y. Zheng, X. Ling, R. Hu, and J. Zhou, A study on influence factors of small punch creep test by experimental investigation and finite element analysis. Materials Science and Engineering: A, 2010. 527(10-11): p. 2784-2789.

17. Olsson, E. and P.L. Larsson, On force-displacement relations at contact between elastic-plastic adhesive bodies. Journal of the Mechanics and Physics of Solids, 2013. 61(5): p. 1185-1201.

18. Li, R., T.H. Hyde, W. Sun, and B. Dogan, Modelling and Data Interpretation of Small Punch Creep Testing, in ASME 2011 Pressure Vessels and Piping Conference 2011: Baltimore, Maryland, USA. p. 1119-1127.

19. Al-Bender, F. and K. De Moerlooze, On the relationship between normal load and friction force in pre-sliding frictional contacts. Part 1: Theoretical analysis. Wear, 2010. 269(3-4): p. 174-182.

20. Cohen, D., Y. Kligerman, and I. Etsion, A Model for Contact and Static Friction of Nominally Flat Rough Surfaces Under Full Stick Contact Condition. Journal of Tribology, 2008. 130(3): p. 031401031409.

21. Kogut, L. and I. Etsion, A Semi-Analytical Solution for the Sliding Inception of a Spherical Contact. Journal of Tribology, 2003. 125(3): p. 499-506.

22. Kogut, L. and I. Etsion, A Static Friction Model for Elastic-Plastic Contacting Rough Surfaces. Journal of Tribology, 2004. 126(1): p. 34-40.

23. Tabor, D., Friction---The Present State of Our Understanding. Journal of Lubrication Technology, 1981. 103(2): p. 169-179.

24. Tabor, D., Junction Growth in Metallic Friction: The Role of Combined Stresses and Surface Contamination. Proceedings of the Royal Society of London. Series A. Mathematical and Physical Sciences, 1959. 251(1266): p. 378-393.

25. Zheng, W., G. Wang, G. Zhao, D. Wei, and Z. Jiang, Modeling and analysis of dry friction in microforming of metals. Tribology International, 2013. 57(0): p. 202-209.

26. Mulvihill, D.M., M.E. Kartal, D. Nowell, and D.A. Hills, An elastic-plastic asperity interaction model for sliding friction. Tribology International, 2011. 44(12): p. 1679-1694.

27. Leu, D.-K., A simple dry friction model for metal forming process. Journal of Materials Processing Technology, 2009. 209(5): p. 2361-2368.

28. Chang, W.R., I. Etsion, and D.B. Bogy, Static Friction Coefficient Model for Metallic Rough Surfaces. Journal of Tribology, 1988. 110(1): p. 57-63.

29. Renouf, M., F. Massi, N. Fillot, and A. Saulot, Numerical tribology of a dry contact. Tribology International, 2011. 44(7-8): p. 834-844.

30. Dymáček, P. and K. Milička, Small punch testing and its numerical simulations under constant deflection force conditions. Strength of Materials, 2008. 40(1): p. 24-27.

31. Zhai, P.-C., G. Chen, T. Hashida, and Q.-J. Zhang, Evaluation on Small Punch Creep Test by Finite Element Method. Key Engineering Materials, 2005. 297-300: p. 377-383.

32. Bowden, F.P. and D. Tabor, The Friction and Lubrication of Solids, ed. C. Press. 1953, Oxford.

33. Wang, L., Y. He, J. Zhou, and J. Duszczyk, Modelling of plowing and shear friction coefficients during high-temperature ball-on-disc tests. Tribology International, 2009. 42(1): p. 15-22. 
34. Rees, D.W.A., Basic Engineering Plasticity, ed. Butterworth-Heinemann. 2006, Oxford: Elsevier Ltd.

35. Hwang, D.H. and K.H. Zum Gahr, Transition from static to kinetic friction of unlubricated or oil lubricated steel/steel, steel/ceramic and ceramic/ceramic pairs. Wear, 2003. 255(1-6): p. 365375.

36. Kraus, H., Creep Analysis, ed. J.W. Sons. 1980, New York: John Wiley \& Sons.

37. Hyde, T.H., A.A. Becker, W. Sun, and J.A. Williams, Finite-element creep damage analyses of P91 pipes. International Journal of Pressure Vessels and Piping, 2006. 83(11-12): p. 853-863.

38. Lin, F.H. and A.A. Tseng, A finite element analysis of elasto-plastic contact problems in metal forming. Materials \& Design, 1998. 19(3): p. 99-108.

39. Li, R., W. Sun, T.H. Hyde, and B. Dogan, Effects of clamping force and specimen design on the response of small punch creep test specimens, in ESIA11 Conference on Engineering Structural Integrity Assessment. 2011: Manchester, UK.

40. Liu, Y. and S. Murakami, Damage Localization of Conventional Creep Damage Models and Proposition of a New Model for Creep Damage Analysis. JSME International Journal Series A, 1998. 41(1): p. 57-65.

41. Semenov, A.P., Tribology at high temperatures. Tribology International, 1995. 28(1): p. 45-50.

\section{List of Figure captions}

Fig. 1 Variation of $\alpha$ with contact pressure, obtained by using equation (3) for a P91 steel at $600^{\circ} \mathrm{C}\left(\sigma_{\mathrm{u}}=310 \mathrm{MPa}\right)$ and different values for Ca.

Fig. 2 Variation of the friction coefficient with the contact pressure for a P91 steel at $600^{\circ} \mathrm{C}$, with strain hardening exponent $\mathrm{n}=0$ and $\sigma_{\mathrm{u}}=310 \mathrm{MPa}$.

Fig. 3 SPCT configuration: (a) rendering of the section of the solid model; (b) dimensions of the test rig [mm].

Fig. 4 Loads and boundary conditions applied to the FE model of SPCT.

Fig. 5 Mesh sensitivity of the variation of contact pressure versus radial coordinate at $25 \%$ of the time to rupture, with a load of $34 \mathrm{~kg}$.

Fig. 6 (a) Swept representation of the 2D axis-symmetric mesh adopted in the FE analyses and (b) detailed view of the mesh in the unsupported region of the specimen.

Fig. 7 Contour plot of the von-Mises equivalent plastic strain, in absolute value, at the beginning of the creep step with load levels of 34 (a), 38 (b) and $42 \mathrm{~kg}$ (c).

Fig. 8 Contour plot of the von-Mises equivalent stress [MPa] at the beginning of the creep step with load levels of 34 (a), 38 (b) and $42 \mathrm{~kg}$ (c).

Fig. 9 Plot of the punch displacement versus time for a load of 34 (a), 38 (b) and $42 \mathrm{~kg}$ (c). $\mathrm{Ca}=3$ for the variable friction coefficient test cases.

Fig. 10 Variation of the contact pressure with normalised radius, , and creep step time for load levels of $34 \mathrm{~kg}(\mathrm{a}), 38 \mathrm{~kg}$ (b) and $42 \mathrm{~kg}$ (c). 
Fig. 11 Plot of the punch displacement versus time for a load of $38 \mathrm{~kg}$ and different values of $\mathrm{Ca}$.

Fig. 12 Distribution of the coefficient of friction, $\mu$, at creep step time $t=0.25 \mathrm{tf}(\mathrm{a}), \mathrm{t}=0.5$ tf (b), t=0.75 tf (c), t=0.99 tf (d), for a load level of $34 \mathrm{~kg}$, over a quarter section of the contact surface.

Fig. 13 Variation of the coefficient of friction with normalised radius, $r / r_{\text {cont }}$, and creep step time for load levels of $34 \mathrm{~kg} \mathrm{(a),} 38 \mathrm{~kg}$ (b) and $42 \mathrm{~kg} \mathrm{(c).}$

Fig. 14 Top surface of an SPCT specimen of a P91 steel at $600^{\circ} \mathrm{C}$. 